\title{
Funding health care in the United Kingdom
}

\author{
Charles Normand
}

This is the eighth in a series of articles responding to the questions raised by the BMA' document, "Leading for Health." The document looks well beyond the coming British election and raises questions about health and health care that will be on the agenda of many countries into the next century.
Health Services Research Unit, London School of Hygiene and Tropical Medicine, London WC1E 7HT

Charles Normand, DPHIL, professor of health policy

BMf 1992;304:768-70
Leading for Health: a BMA Agenda for Health ${ }^{1}$ raises a number of questions about the funding of health services. In addition to funding mainly from general taxation, the document considers social insurance, a hypothecated tax, payments and copayments by individuals, private insurance, funding through local government, voluntary contributions, and income generation. It goes on to consider the level of funding for health services and the questions of what is the appropriate level and how that level might best be determined. The third set of funding questions relate to the allocation of the funds over the different health and social care programmes and the factors that should determine the allocation.

\section{Methods of funding}

Spending on health care in the United Kingdom was $5.8 \%$ of the gross domestic product in $1989^{2}$ and is unlikely to be very different in $1992 .{ }^{3}$ Most of this $(87 \%)$ is public spending on health services.

The countries that are near the bottom of the league table in terms of percentage of gross domestic product spent on health services typically fund services through general taxation (for example, Spain, Denmark, Portugal) and those with higher proportions typically have social insurance arrangements on the Bismarkian model (Germany, the Netherlands, Austria). However, once the level of income in the country is taken into account (and in general richer countries spend higher proportions of income on health), the link between the funding mechanism and the proportion of gross domestic product spent is weak.

In considering the mechanism for funding health services it is useful to start with some principles. These are listed in the box.

\section{HYPOTHECATED TAXES}

The arguments against hypothecated taxes are that they incur high collection costs; are subject to fluctuations in receipts; and cannot be directly compared with other government programmes, some of which may make a significant contribution to the health of the population. It should be an aim to minimise the cost of collecting the revenue, and if a tax for health were separate from existing mechanisms collection costs would rise. Public enthusiasm for spending on health would probably mean that there would be relatively little opposition to increases in the health tax, which could conflict with the government's objectives in terms of overall taxation and spending.

It is not clear why the government should object if the public chooses higher spending on health services funded fully by higher taxes. In terms of the macroeconomic effects there is no difference between public or private spending on health services of a given amount, and there has been no suggestion that the government should restrict voluntary spending on health. High spending on health will have some macroeconomic effects, ${ }^{4}$ but these may be acceptable to the public.

Variations in the receipts arise if a tax has a narrow and unstable base. For example, a payroll tax rises when the rate of employment and wages rise and falls in

\section{Principles for funding health services}

- The cost of collecting the funds should be low

- The system should be equitable

- The funding should be adequate and not be subject to fluctuations

- The system should not lead to conflict with other government objectives

- The public should be satisfied with the system

- The system should not channel funds into low priority programmes or away from high priorities

a recession, when the number of unemployed people rises. Given that health care needs do the opposite, a tax on earnings has problems. A sales tax to fund health services has the same risk of giving falling receipts during recessions.

There are mechanisms that can avoid some of the problems of variations. For example, the tax can be paid from general government funds for unemployed people (as in the new Czech system). It is also possible to vary the rate of the health tax so as to keep the yield constant. However, this conflicts with other government objectives. Increasing a payroll tax or a sales tax during a recession is likely to lead to a fall in demand and a rise in unemployment.

There are also some fears that a special health tax would fall disproportionately on poorer people. There is no reason why this should be so, but taxes such as national insurance in the United Kingdom are regressive (that is, the proportion of income paid is higher for those with lower incomes). It would be possible to devise a health services tax that is progressive if this were desired. In general the issue of equity is best seen in the context of the overall burden of taxation. The present tax system has little progression (that is, the proportion paid by those with high incomes is similar to that for the lower paid).

In summary, in terms of the principles suggested in the box, a hypothecated tax would probably increase collection costs and might lead to fluctuations in yield. It would be more popular with the public, but less popular with the Treasury. The visibility of the payment and the total resources devoted to health services might make patients and providers more aware of the costs of treatment and care. There is no guarantee that the rate would be set at a level that would provide adequate funding - a hypothecated tax is still under the control of the government-but popular pressure could allow selective increases in the health tax.

\section{SOCIAL INSURANCE}

Social insurance is really a variant of the hypothecated tax. Contributions are on the basis of ability to pay and are not actuarially fair. Its main differences from funding from general or hypothecated taxation comes from different attitudes. Social insurance tends to use the language of insurance, with specified entitlement to specified cover. ${ }^{5}$ This contrasts with the more general entitlement to care under most tax funded systems, notwithstanding the patient's charter. It is difficult to 


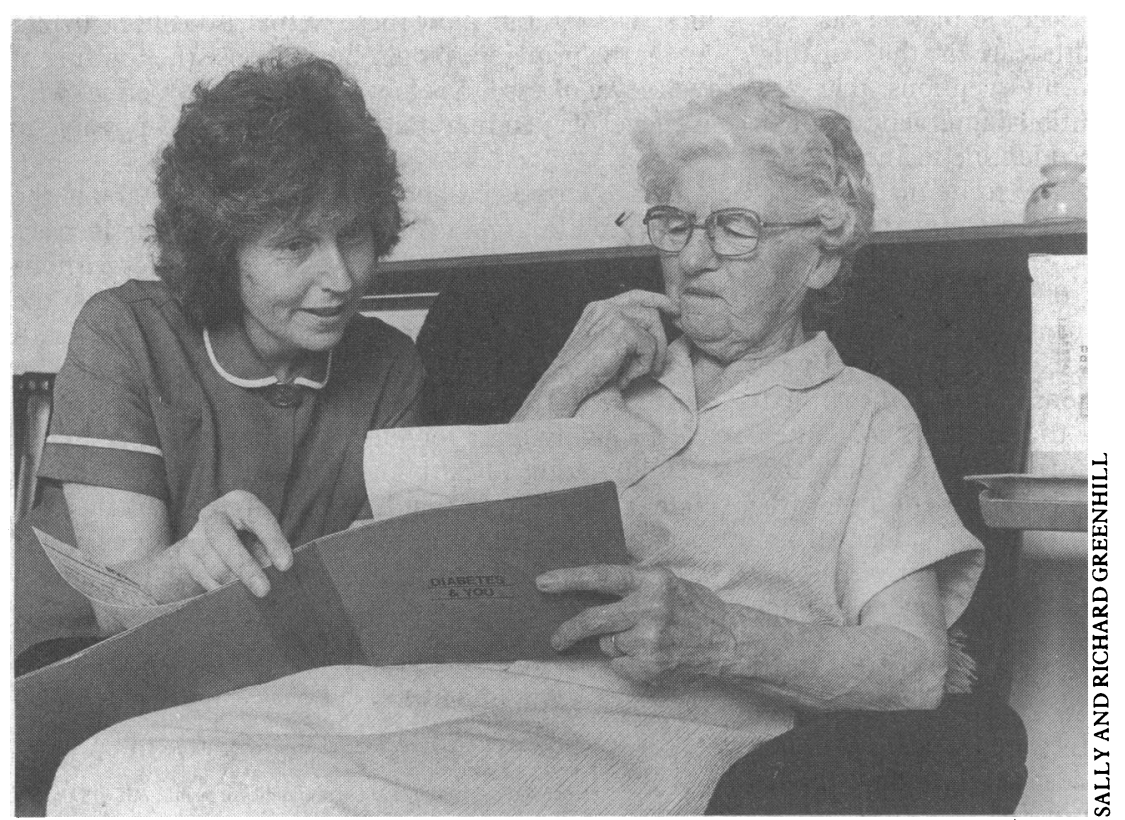

The aging of the population will necessitate increased expenditure on continuing care and treatments for conditions that are not life threatening

be sure whether this difference in attitude is really due to the framework of insurance or to differences in the culture of countries.

\section{PAYMENTS AND COPAYMENTS}

The argument for direct payment for services by patients is that this prevents use of services where the costs exceed the benefits. Services provided free at the point of use will always have excess demand. ${ }^{4}$ However, it is difficult to devise a system of payments that does not also deter people who would benefit significantly. Means testing is inefficient and costly to administer.

It is worth distinguishing two arguments. Firstly, the uncertainty about the need for services by an individual patient means that some form of insurance is needed. This means that government funding or some form of insurance is always likely to be chosen. As with all insurance, copayments can be only a small proportion of the cost in large claims. There is at most a limited role for payments by individual people for high cost services that have uncertain demand by each person. In principle people do not need insurance for health service needs that are entirely predictable, such as routine dental and eyesight checks, as they can predict the costs with certainty and put aside funds for these purposes.

Secondly, the purpose of funding by taxes and social insurance is partly to offer a service irrespective of ability to pay. Payments and copayments conflict directly with this objective. Use of health services has been shown to fall as copayments rise, but demand is inelastic. $^{78}$

Copayments can be useful in discouraging frivolous use of services but will never be a source of a large proportion of the funds for health services.

\section{PRIVATE INSURANCE AND EMPLOYER BASED SCHEMES}

The arguments against the use of private insurance as the main source of health services funding have been well rehearsed, ${ }^{+}$and the advantages of this system are few. A more interesting question is that of the role of private insurance to supplement public spending. The higher proportion of gross domestic product spent on health in Germany and the Netherlands as compared with the United Kingdom is largely explained by the difference in private funding - that is, spending on services in addition to the government scheme. ${ }^{26}$ Germany spent an average of 200 European currency units (ecu) per capita on private health care in 1977, as compared with 89 ecu in the United Kingdom. The Netherlands spent 236 ecu per capita in 1987 on private care.

Funding by employers has a tendency to reduce the level of employment, and leaves those in casual employment and those unemployed without cover. Administrative costs are high, and the source is subject to fluctuations. Employers may offer supplementary medical cover as a tax efficient part of the overall remuneration, but this leads to distortions in the allocation of resources. As a mechanism it has little to recommend it.

There is frequent political criticism that private insurance is interested only in profitable, low cost care and does not cover expensive and unpredictable treatment and care. This is largely true and is likely to continue. ${ }^{9}$ In so far as the treatment would otherwise have been administered by the NHS (possibly after a delay), the contribution of the private sector relieves pressure on public funding. There is, however, a risk that the government's commitment to funding will be reduced to take account of the private spending.

In terms of the principles suggested in the box private spending is expensive to collect and administer, conflicts with equity objectives by giving unequal access, and is a fluctuating and unreliable source of funds. If private spending displaces public spending these problems are serious. If it is genuinely supplementary, then the costs fall on those who choose to spend money on private insurance. Tax relief on private policies may increase the contribution by private patients to the cost of their care, but at the cost of devoting government resources to a relatively low priority group.

\section{MULTIPLE SOURCES OF FUNDING}

The use of several different sources of funding for any overall level of spending means that the costs of administration are high. There therefore should be a prejudice against this approach. The only reasons to choose to use many sources are related to allocation of health services, the possibility of increasing overall funding, and encouraging innovation and diversity. For example, social security funding has allowed the development of different patterns of residential and nursing home care for elderly people. In general multiple sources of funding might be expected to work against efficient resource allocation, but some neglected high priorities may possibly come to light.

\section{SUMMARY OF CHOICES}

Decisions about the overall level of funding are essentially political. Changes in the mechanism might make health services expenditure more acceptable, and therefore increase the total. It would, however, be unwise to expect resource constraints to be significantly relaxed by changing the funding mechanism. Hypothecated taxes might allow some increase in funding, and, if offered as social insurance, might lead to clearer entitlements to services. A serious danger is that of changing to a funding mechanism which consumes more resources in the process of raising the revenue.

\section{Level of funding}

In principle it is possible to define the appropriate level of spending on health services-that is, health spending is a priority so long as an additional pound spent on health services yields greater benefits than it would in other government or private spending. It is, however, difficult to put this into practice.

It would be easier, however, to move towards this type of calculation if better data were available on the costs and effectiveness of health care interventions and 
other spending options. It is easier to make a case for additional spending on health care if the existing programme concentrates on interventions that are clearly high priorities and additional interventions that offer significant benefits can be identified. The case for higher levels of funding will have to be made on the basis of a demonstration of the cost effectiveness of additional spending.

International comparisons of spending are sometimes misleading as they take no account of differences in the cost of providing services and the efficiency of provision. However, comparisons show that the United Kingdom spends less than the average for other developed industrialised countries, and has held the proportion of gross domestic product spent on health nearly constant over 10 years. There is evidence from opinion polls that the public are in favour of higher spending. Experience in other countries suggests that it is possible to remain prosperous at the same time as devoting a larger share of gross domestic product to health care.

If increases in overall health care expenditure are to be justified on grounds of cost effectiveness many developments will be in continuing care and in the expansion of established treatments for conditions that are not life threatening. ${ }^{+}$The effects of the aging of the population are mainly to increase needs in these areas. It also will not be easy to justify additional funding for those parts of the country that are already relatively well funded until a more equal distribution is achieved.

There is no reason to believe that the present mix of spending on prevention, health promotion, primary care, secondary care, and tertiary care reflects the pattern of cost effective available interventions. Too little data exist to allow these comparisons to be made. Again the principle should be to choose the funding of each level of care to achieve the maximum effect with any level of spending, but it is not currently possible to do this.

I have suggested above that the debate about the level of funding will in future be conducted on the basis of identifying additional, cost effective interventions that have a higher priority than other spending in the public and private sectors. As needs for care grow, with the additional opportunities provided by advances in medicine and the aging population, many opportunities will probably exist for identifying high priorities for spending within health and personal social services. ${ }^{10}$ Higher spending on health and social care is likely to be acceptable to the public but will bring with it a greater need to demonstrate the effectiveness and cost effectiveness of interventions.

1 BMA. Leading for health. A BMA agenda for health. London: BMA, 1991 2 Sheiber G, Poullier J-P, Greenwald L. Health care systems in twenty four countries. Health Affairs 1991;10:22-38.

Robinson R. Health expenditure: recent trends and prospects for the 1990 s. Public Money and Management 1991;11:19-29.

4 Normand C. Economics, health, and the 2029 . $1572-7$

5 Cichon M. Health sector reforms in central and eastern Europe. International Labour Review 1991:130:3.

6 Figueras J, Normand C, Roberts J, McKee M, Hunter D, Karokis A, et al. Health care infrastructure needs of the lagging regions. Report to the Commission of the European Communities. London: London School of Hygiene and Tropical Medicine, 1991

7 Phelps C, Newhouse J. Co-insurance and the demand for health care. Santa Monica: Rand Corporation, 1974

8 McGuire A, Henderson J, Mooney G. The economics of health care. London: Routledge and Kegan Paul, 1988.

9 Proper C, Maynard A. Whither the private health care sector. In: Culver A, Maynard A, Posnet J, eds. Competition in health care-reforming the NHS. London: Macmillan, 1990

10 Bosanquet N, Gray AM. Will you still love me? New opportunities for health services for elderly people in the 1990 s and heyomd. Birmingham: Natior Association of Hospitals and Trusts, 1989.

\title{
Agenda for health: an economic view
}

\author{
Cam Donaldson
}

Leading for Health: a BMA Agenda for Health poses some searching questions on funding of health care: "How much should be spent on the health and community care services? How can that amount be determined?"' Unfortunately, the suggested approach to analysing these questions is flawed. In this article I explain why this is the case and what the role of economics should be in setting an agenda for health, in particular in setting the health care budget.

\section{How not to set an agenda: international comparisons}

Often, much is made of data on mortality, morbidity, and health care expenditure across countries (usually those in the Organisation for Economic Co-operation and Development (OECD)). An "international comparisons industry" has become established, using such data not because it tells us what we want to know but rather because it's there. The BMA's agenda falls into the same trap. On the one hand the document claims that there is no " "right' amount to spend on the NHS." On the other hand it contains several international comparisons, implying that there is a magic number (of pounds spent on health care) to which all societies should be moving: "If Britain were to bring its expenditure up to the average for OECD countries then about another six billion pounds would be needed for the health service this year."

One problem with such comparisons is that health care is defined differently in different countries. It is well known that one of the reasons why Sweden seems to spend more than the United Kingdom is that Sweden has one of the highest rates of placing elderly people in institutions. Expenditure on these institutions is included in Sweden's total expenditure on health care. So like is not being compared with like.

Even if expenditure was defined similarly across countries, international comparisons would still be $\mathrm{S}$ flawed. From the 21 OECD countries for which a comparison can be made (table) take Australia, for o instance. ${ }^{2}$ Some countries spend less than Australia and achieve better health outcomes (for example, Denmark and Japan); other countries spend more but . do not necessarily do better on outcomes (for example, $\tilde{\omega}$ the United States and France). Can anything be inferred about the allocation or misallocation of health 0 care resources in Australia? Unfortunately not. The mortality data are crude indicators of health. They are ? not measures of the potential product of health care. Health care is productive only if it improves mortality or morbidity or prevents deterioration.

The use of international comparisons is naive. Not $\stackrel{\mathbb{D}}{\stackrel{D}{2}}$ surprisingly, when based on such methods, a judgment of the effective impact of health care is elusive. It 8 always will be, no matter how good the data are in the future. It is the method that is at fault. We need methods which tell us, within a country, what are the costs and benefits of changing the current uses of health care resources and of expanding or contracting the health care budget relative to other health producing activities. 